\title{
Myter og sannheter om israelske kibbutzer
}

Tusentalls skandinaver har vært frivillige på kibbutz i Israel. Ifølge myten er disse kollektive jødiske bosetningene basert på egalitære, sosialistiske, progressive og demokratiske ideer. Stemmer disse idealene med kibbutzenes rolle i den sionistiske kolonialisering og etniske rensing av Palestina, samt diskriminering mot både palestinere og ikkeeuropeiskættede jøder? 
TEKST: Tilde Rosmer

ківвUTZ NORGE skulle være gaven til den unge, jødiske staten fra norske arbeidsfolk etter den tragiske flyulykken på Hurum i I949, hvor 26 jødiske barn fra Nord-Afrika døde på vei til det som skulle være en avslappende sommerleir i Norge, før de emigrerte til Israel. Tynget av skyldfølelse fra 2 . verdenskrig, og som minnesmerke for ulykkesofrene, arrangerte Arbeiderpartiet en innsamlingsaksjon for å etablere et "nybrott i Israel" - en "kibbutz Norge" i ørkenen. "We should there form a part of the wall of defense for Europe in Asia, an outpost of civilisation against barbarism," skrev sionismens "far", den ungarske jøden Theodor Herzl. ${ }^{2}$ I tråd med Herzls idé om den jødiske staten i Palestina som sivilisasjonenes utpost, ville Arbeiderpartiet bidra til å styrke den unge staten omringet av arabere som, ifølge partiets ledelse, drev med herjinger og terror og lot landet forfalle. ${ }^{3}$

Etter mange runder med pengeinnsamling fra nordmenn i en hard etterkrigstid, ble Kibbutz Norge en realitet, og familien til den eneste overlevende fra flyulykken på Hurum fikk sitt hjem. Forbauselsen og skuffelsen var stor da norske besøkende observerte at den nord-afrikanske familien ikke var godt likt av de andre familiene i kooperativet. Omtalt som "kulturelt og åndelig tilbakestående" fra "kummerlige kår og uhyggelige forhold", ble ikke de egalitære dørene åpnet for den ikkeeuropeiske jødiske familien. ${ }^{4}$

Denne historien er et eksempel på mistillitsforholdet mellom jøder fra Europa og jøder fra Midtøsten og Nord-Afrika som fremdeles er tilstede i Israel. Dette er lite kjent i Norge. I dagens post-sionistiske israelske kritikk er myten om kibbutzen som et sosialistisk prosjekt bygd på egalitære verdier avslørt som åpent kun for visse jøder - de av europeisk opprinnelse. Denne kritikken var tydelig i rettsaken om landrettigheter frontet av bevegelsen HaKeshet HaDemokratit HaMizrahit (Den demokratiske mizrahi regnbuebevegelsen - mizrah er øst på hebraisk og termen mizrahi/m viser til jøder fra Midtøsten og Nord-Afrika) som argumenterte at askenasiske (europeiskættede) jøder ble favorisert i fordelinger av disse rettighetene, på bekostning av jøder fra arabiske og muslimske land.

\section{Sionistisk kolonialisering av Palestina}

Ifølge Arbeiderpartiets innsamlingskampanje til Kibbutz Norge på slutten av I940tallet, var jorda i Palestina "vanskjøttet gjennom århundrer".5 De norske sosialistene kjøpte den sionistiske myten om "et 
land uten folk for et folk uten land". I virkeligheten var denne jorda i stor grad pløyd av palestinske bønder før sionistiske jøder kom til Palestina fra slutten av i8oo-tallet. Mer enn 700 ooo palestinere flyktet eller ble tvangsevakuert før, under og etter krigen i i948. ${ }^{6}$ Omtrent I60 ooo palestinske arabere ble igjen i det som ble Israel. ${ }^{7}$ Men palestinerne var glemt eller ignorert når nordmenn skulle bygge Kibbutz Norge som "et bindeledd mellom Norge og Israel". ${ }^{8}$ Palestinerne er også glemt eller oversett på dagens hjemmesider for organisasjonene Svekiv og Dankiv som arrangerer kibbutzopphold for unge skandinaver. ${ }^{9}$

Ifølge Svekiv har organisasjonen frem til i dag arrangert mer enn 30 ooo slike opphold. De frister unge skandinaver med bilder av en palestinsk brødselger, av Klippemoskeen og Damaskusporten i Gamlebyen, samt av Getsemanehagen uten å informere om at disse attraksjonene er i Øst-Jerusalem som er okkupert av Israel. Det nevnes heller ikke at den eksotisk avbildede palestinske beduinen i Naqab-ørkenen ${ }^{\text {ro }}$ representerer den mest diskriminerte og på alle måter mest marginaliserte befolkningsgruppen i Israel. Majoriteten av beduinene i Naqab lever i såkalte "ikke-anerkjente landsbyer" uten vann, kloakk og strøm, og mangler tilgang til skole og helsetjenester. De ble tvangsflyttet fra sin fruktbare oppdyrkede jord til disse kummerlige kårene av staten etter I948. ${ }^{\text {II }}$

Poenget her er at det norske "Arbeiderpartiets blinde kjærlighet" for "mønstersamfunnet Israel" la grunnlaget for en beundring fra "Israels beste venn" som så seg blind på det som ble oppfattet som et sosialistisk "meningsfellesskap". ${ }^{\text {22 }}$ Blind fordi Norge, misledet av Arbeiderpartiet, ikke så den jødiske statens kolonialisering av Palestina eller dens diskriminerende behandling av innfødte palestinere og ikkeeuropeiske jødiske immigranter. Med hensyn til frivillige på kibbutzer har denne blindheten hatt gyldighet opp til den andre Intifadaen (Det palestinske opprøret) som startet høsten 2000. Siden da har antallet internasjonale frivillige gått ned..$^{13}$

\section{Ideologiske unge frivillige}

Interessant nok tok populariteten av kibbutzopphold for unge frivillige av på slutten av I96o-tallet - etter den israelske okkupasjonen av Vestbredden og Gaza i I967. Mer enn 350 ooo personer fra 35 forskjellige land har jobbet frivillig i en kibbutz siden I967. ${ }^{\mathrm{I}}$ Som frivillig arbeider en sammen med kibbutzmedlemmene etter ideologien "yte etter evne, og motta etter behov". ${ }^{15}$ Israelere over 18 år som bor fast $i$ en kibbutz er medlemmer, og det er i gjennomsnitt 500 medlemmer per kibbutz. Alle får lønn etter sivil status, mens frivillige jobber for kost, losji og lommepenger. Tidligere drev kibbutzene mest med jordbruk, men i de siste tiårene har mange kibbutzer opprettet industrivirksomhet og servicebeskjeftigelser.

Tradisjonelt spises alle måltider i en felles spisesal drevet av kibbutzmedlemmene, tøy vaskes i et felles vaskeri, og de fleste praktiske oppgaver kan utføres innenfor kibbutzens område uten kostnader. ${ }^{16}$ Medlemmene bor i forholdsvis små enheter i samsvar med sivil status og plassbehov. Ofte bor flere frivillige sammen i enkle rom med delt dusj og bad. ${ }^{\text {17 }}$ Det første som ble bygd da en kibbutz ble etablert var gjerdet, for å holde uønskede arabere ute, og vanntårnet, som også fungerte som utkikkstårn. Alle kibbutzer er fremdeles 
inngjerdet og bevoktet av israelske soldater.

Ifølge Israels utenriksdepartement ble den første kibbutzen opprettet i iو०9 av en gruppe jødiske pionerer som bestemte seg for å arbeide og bo på en felles uavhengig gård i Galilea. ${ }^{18}$ Ved begynnelsen av 2. verdenskrig var det tretti kibbutzer i Palestina, alle etablert av sionistiske, hovedsakelig russiske jøder som trodde at gjennom arbeid med jorda ville en ny jødisk identitet bli skapt. Denne nye identiteten skulle videre være grunnlaget for deres politiske mål - å etablere jødiske bosetninger i

\section{De norske sosialistene kjøpte den sionistiske myten om "et land uten folk for et folk uten land".}

Palestina. "Målet var at bygge et jødisk sammenhold, hvor mennesker skulle arbejde med jordbrug og håndværk og på denne måde opnå social, økonomisk og national frihed. De demokratiske arbejdsforhold bidrog i høj grad til en øget produktion og gjorde det lettere, for det jødiske folket at bosætte sig i Palæstina." ${ }^{\text {I9 }}$

I en artikkel i den israelske avisen Haaretz fra 2005 beskrives blonde skandinaviske hippier som kom til kibbutz for å "bevitne underet i Midtøsten". ${ }^{\circ}$ Ifølge artikkelen møtte disse tidligere frivillige det som er beskrevet som et "idealistisk og uskyldig fellesskap" i kibbutzene. Hjemvendte frivillige er beskrevet som "good-will ambassadors" for Israel. ${ }^{21}$ Disse Israel-vennene opprettet kibbutzorganisasjoner som Svekiv og Dankiv for å promotere kibbutzopphold, og noen dro til og med til Israel for å hjelpe under I973- krigen. ${ }^{22}$ Artikkelens undertittel, "Mange beklager seg over at det ikke er flere ideologiske frivillige, bare thaiarbeidere", gir oss en pekepinn om den kapitalistiske og ikke fullt så ideologiske utviklingen i kibbutzene de siste tiårene.

\section{Kibbutz på palestinsk land}

Ifølge organisasjonen Med Israel for fred $(\mathrm{MIFF})^{23}$ er det i dag 268 kibbutzer spredd over hele Israel: “I sør dyrker de opp ørkenen. Israel er det eneste landet i verden hvor ørkenen blir mindre. Kibbutzene var og er fremdeles viktige for oppdyrkingen av landet." ${ }^{24} \mathrm{Ti}$ av disse kibbutzene ligger i de okkuperte syriske Golanhøydene, men dette opplyses verken av MIFF, Svekiv eller Dankiv. ${ }^{25}$

Kampen om land er det mest sentrale punktet i konflikten mellom Israel og palestinerne. I I948 tok Israel I8 643 kvadratkilometer av 20325 kvadratkilometer, eller 92 prosent av det som etter I948krigen var israelsk område og plasserte det under hva staten kalte "the Custodian of the Absence (Landowners) property". ${ }^{26} \mathrm{I}$ praksis vil dette si at disse landområdene ble utilgjengelige for de gjenværende palestinske eierne og landbrukerne. Ifølge den palestinske forskeren Abu Sitta ble det meste av dette landet leaset til kibbutzer og andre kooperative jødiske samfunn. ${ }^{27}$ Omtrent 80 prosent av alt statseid land i Israel kontrolleres av forskjellige jødiske organisasjoner. Dette forhindrer også i dag palestinske statsborgere av Israel å kjøpe og leie dette landet, fordi de jødiske organisasjonene er sionistiske og derfor forbeholder salg og utleie til jødiske statsborgere. På hjemmesiden til Israel Land Administration informeres det om at " $93 \%$ of the land in Israel is public domain; that is, either 
property of the state, the Jewish National Fund (JNF) or the Development Authority. The Israel Land Administration (ILA) is the government agency responsible for managing this land which comprises 5,750,000 acres. 'Ownership' of real estate in Israel usually means leasing rights from the ILA for 49 or 98 years." ${ }^{29}$

Menneskerettighetsorganisasjonen for palestinske statsborgere i Israel, Adalah ("rettferdighet" på arabisk), gikk til sak mot denne diskriminerende landpolitikken i Israel ved FNS Kommisjon for menneskerettigheter i samarbeid med Habitat International Coalition. De argumenterte

\section{Omtrent 80 prosent av alt statseid land i Israel kontrolleres av forskjellige jødiske organisasjoner.}

med at til tross for at den palestinske nasjonale minoriteten i Israel utgjør 20 prosent av befolkningen, kommer den statlige fordelingen av land nesten uten unntak kun jødiske borgere til gode. Ifølge Adalah vil en fortsettelse av denne diskriminerende praksisen resultere $i$ en institusjonalisering av apartheid-lignende bosetningsmønstre hvor israelske statsborgere er totalt segregert etter rase og etniske kriterier.

Den israelske akademikeren Oren Yiftachel bruker konseptet "etnokrati" for å beskrive den israelske staten og dens forfordeling av ressurser og rettigheter til jødiske innbyggere. ${ }^{3 \circ}$ Yiftachel har definert etnokrati som en type nasjonalisme som har som mål å "etnifisere” et omstridt territorium og samfunn. Ifølge Yiftachel er der- for et etnokrati ikke demokratisk, men siden det tillater en viss grad av deltagelse for statsborgere av andre etnisiteter, er et etnokrati heller ikke autoritært. Det israelske etnokratiet beskrives videre som fundamentert i en rigid etno-nasjonalisme, $i$ en kolonialistisk bosetningsstat med et stratifisert sosialt hierarki som følger logikken til det Yiftachel kaller "etnisk kapital".

Et eksempel på kibbutzenes rolle i dette etnokratiet er Kibbutz Shuval i Naqab. Kibbutzen er etablert i et område som før I948 var befolket av arabiske beduiner som hadde bodd der i generasjoner. Etter etableringen av den jødiske staten ble de arabiske beduinene som ikke ble utvist, lagt under den militære administrasjonen som majoriteten av arabiske palestinere i Israel. $^{31}$ De gjenværende beduinene fikk ordre om å flytte, og Kibbutz Shuval ble etablert på den fruktbare jorda..$^{22}$ I dag bor disse beduinene og deres etterkommere $\mathrm{i}$ en av de såkalte "ikke-anerkjente landsbyene" uten fasiliteter og infrastruktur som veier, strøm, vann, kloakk, skole og helsetjenester - rettigheter som tilkommer dem som statsborgere av staten Israel. Som det kommer frem i intervjuene i Adalahs film «The Unrecognized», er ikke beduinene lenger bønder, fordi jorda der de ble tvangsflyttet til ikke egner seg for jordbruk.33 I stedet jobber de i lavtlønnede dagjobber på jødiske israelske fabrikker eller for kibbutzen på jorda de en gang eide. ${ }^{34}$

\section{Etnisk jødisk sosialt hierarki}

I tillegg til palestinske statsborgere av Israel og palestinere under okkupasjon og $\mathrm{i}$

Øverst: Golda Meir, tidligere statsminister i Israel, på besøk i en kibbutz.

Nederst: Kibbutzen i Ramat Babel i I927. 

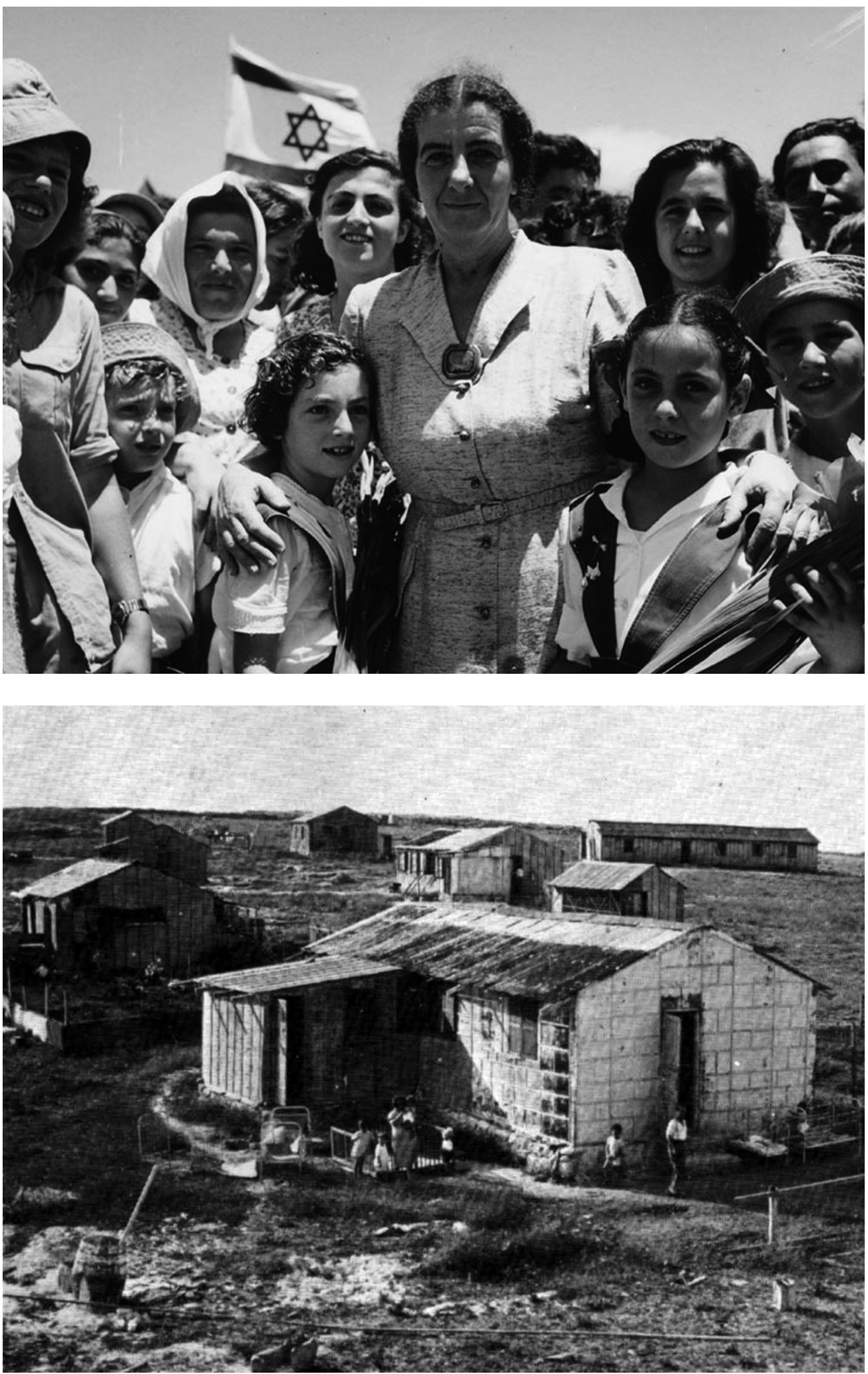
eksil, er ikke-europeiske jødiske israelere skadelidende i det israelske etnokratiske statssystemet. Av Israels befolkning bor kun 2,5 prosent i kibbutz, men kibbutzene rår over det meste av den fruktbare jorda i landet. Videre er de fleste kibbutzmedlemmer av askenasisk opprinnelse. Jøder fra arabiske og muslimske land ble bosatt av staten i såkalte "Development Towns",

\section{Blonde skandinaviske hippier kom} til kibbutz for å "bevitne underet

\section{i Midtøsten".}

geografisk perifere, små urbane bosetninger, i hovedsak nord og sør i landet. Før den russiske immigrasjonen på I990-tallet utgjorde jøder fra arabiske og muslimske land 75 prosent av innbyggerne $i$ disse byene. ${ }^{35}$ Innbyggerne i "Developement Towns" ligger lengst ned av alle jødiske israelere på økonomiske og sosiale statistikker, og få av innbyggerne har universitetsutdannelse eller høytstående posisjoner i byråkratiet eller i militæret. ${ }^{36}$

På bakgrunn av disse faktorene valgte Den demokratiske mizrahi regnbuebevegelsen på slutten av I990-tallet å gå til sak mot staten på grunn av det bevegelsen anså som ulik fordeling av nasjonalt eid land, til fordel for kibbutzene. Regnbuebevegelsen var i mot ILAs avgjørelse om å omdefinere jordbruksland til boligbygging og andre formål enn landbruk. Grunnen var at en slik omdefinering, ifølge Regnbuebevegelsen, ville komme den lille gruppen av askenasiske kibbutzmedlemmer til gode. Kibbutzene har allerede profittert på denne jorda som de har leaset fra staten siden
I948. Videre hevdet Regnbuebevegelsen at jødiske innbyggere fra arabiske og muslimske land aldri hadde blitt tilbudt å lease eller leie jord på samme måte, og derfor aldri hadde vært $\mathrm{i}$ stand til å utnytte de nasjonale landressursene. ${ }^{37}$ Med slagordet "Dette landet er også mitt/vårt" gikk Regnbuebevegelsen til sak. Kibbutzbevegelsen svarte med slagordet: "Den Demokratiske Mizrahi Regnbuebevegelsen er for retten til tilbakevendelse" - underforstått: for alle palestinske flyktninger. Fordi majoriteten av den israelske befolkningen anser en tilbakevendelse av palestinske flyktninger som den demografiske slutten på den jødiske staten, brukte kibbutzbevegelsen dette slagordet for å delegitimere Regnbuebevegelsen og deres sak.

Poenget er at medlemmene i Regnbuebevegelsen føler seg diskriminert fordi de er ikke-europeiske jøder og hevder at denne diskrimineringen er institusjonalisert $\mathrm{i}$ forhold til distribusjon av nasjonale ressurser. Ifølge den israelske akademikeren og aktivisten Shiko Behar bruker staten store summer på kibbutzene, men lite på å forbedre levevilkårene til den hovedsaklig ikke-askenasiske arbeiderklassen. I hans artikkel "Stop the Occupation or Stop the Kibbutzim?" konkluderte Behar at rasisme er årsaken til forskjellen mellom det beskjedne beløpet gitt av myndighetene til å restaurere boligstrøk dominert av ikkeeuropeiske innbyggere det siste tiåret, og de store summene til ettergivelse av kibbutzenes lån. ${ }^{38}$ Hvorfor ellers behandle forskjellige sosiale grupper forskjellig, spør han retorisk.

Som beskrevet av Yiftachel over, er en av manifestasjonene av det israelske etnokratiet et stratifisert sosialt hierarki hvor etniske grupper er plassert i forhold til 
hverandre. I dette ikke-egalitære systemet er fremdeles askenasiske jøder øverst, etterfulgt av immigranter (jøder og ikkejøder) fra det tidligere Sovietunionen, deretter kommer i dag jøder fra arabiske og muslimske land, så etiopiske jøder, og til slutt palestinske statsborgere og palestinere under okkupasjon. Ifølge den israelske akademikeren Gershon Shafir ble grunnlaget for dette hierarkiet dannet allerede etter det som kalles den første aliyah (oppstigelsen på hebraisk; begrepet brukes til å benevne jødisk immigrasjon til Eretz/Landet Israel), den første bølgen av jødiske sionistiske immigranter til Palestina fra I882-1903. ${ }^{39}$ Shafir beskriver hvordan kolonialiseringen av Palestina i den første aliyah tok form av et samfunn basert på jødisk kontroll og overmakt. Dette ble videre utvidet til å danne et etnisk jødisk arbeidsmarked stengt for palestinske arabere. Derfor trengte jødiske arbeidsgivere jødiske arbeidere. Dette gjaldt også i kibbutzene. På denne bakgrunnen vendte sionistiske europeiske jøder seg til sine trosfeller i arabiske og muslimske land.

Alt på I80o-tallet ble jemenittiske jøder leid inn som billig arbeidskraft i kibbutzene, fordi de kunne "arbeide som arabere” - det vil si at de var trodd å tåle hardt arbeid $\mathrm{i}$ intens varme og ansett som villige til å arbeide for dårlig lønn..$^{\circ} \mathrm{De}$ jemenittiske jødene ble ikke inkludert som medlemmer i de første kibbutzene. Med andre ord ble ikke disse ikke-europeiske jødene inkludert i det egalitære, demokratiske og sosialistiske samfunnet, fordi de var annerledes - de passet ikke inn slik de europeiske kibbutzmedlemmenes orientalistiske øyne så det. Jøder fra arabiske og muslimske land ble sett på som "kvantitet" og ikke "kvalitet". ${ }^{4 \mathrm{I}}$ De var "naturlige" arbeidere, mens europeiske sionistiske jøder var "siviliserte" og "idealistiske" pionerer..$^{42}$ I samme orientalistiske ånd uttalte en begeistret Lo-delegasjon etter en reise til Israel i I963 at israelerne hadde skapt en demokratisk oase i Midtøsten "preget av motsetninger og spenning. (...) Høyt kultiverte mennesker med allsidig utdannelse fra Europa og UsA skal smeltes sammen med primitive jødiske minoriteter fra Nord-Afrika og Asia". ${ }^{43}$

Sammenhengen mellom diskrimineringen og den påfølgende marginaliseringen av jøder fra arabiske og muslimske land og palestinere, ble nylig beskrevet i en artikkel av to medlemmer av Regnbuebevegelsen, antropologen Smadar Lavie og den erfarne aktivisten Reuven Abarjel. Artikkelen ble publisert under krigen i Libanon i sommer:

"Mizrahim provide the demographic majority on whose civic docility the Eurocentric Israeli regime rests. Mizrahim have been the Jewish labor turning the cogs of the European-Zionist colonial project ever since its inception, with the Yemeni-Jewish labor migration of 1882. Mizrahim freed Zionism from its total dependency on indigenous Palestinian labor. Mizrahim were the Zionists' 'natural laborers', employed in near-slavery conditions. In order for Mizrahim to work with efficacy, the Zionist hegemonic patriarchy ruptured Mizrahi extended families. For themselves, they used the appellation 'ideological laborers', and went on to found Israel's socialist-liberal Left." ${ }^{4}$

Dette står i klar kontrast til det som presenteres av MIFF som "unge idealister som ønsket å bygge opp fedrelandet på nytt, på flukt fra hat og utslettelse i Europa og Russland. De hadde vært medlemmer av sosial- 
istiske bevegelser i sine tidligere hjemland, og i Israel satte de sine idealer ut i livet." ${ }^{45}$ Tydeligvis skulle ikke de idealistiske verdiene gjelde for alle jøder, kun noen var inkludert i "fornyelsen" som skulle "forsøke å skape en ny mennesketype som lever opp til sosialismens idealer". ${ }^{4}$

\section{I solidaritet med hvem?}

Kibbutz Norge ble beskrevet som arbeiderbevegelsens lille paradis i Israel, men teksten "en nybyggerkoloni i ørkenen, med det store åpne landskapet, den viftende palmen, vanntårnet og de lave husene", gir i dag konnotasjoner til andre israelske nybyggerkolonier i det okkuperte palestinske området. ${ }^{47}$ Vestbredden er nå omringet av en flere meter høy mur som i stor grad er bygd inne på okkupert palestinsk land med høye utsiktstårn hvor bevæpnede israelske soldater holder vakt. På denne måten blir ideen om et etnisk renset territorium som fremdeles må beskyttes holdt ved like, men med mer radikale og dramatiske tiltak. Shafir beskriver hvordan sosialismen i Israel fikk en spesiell udemokratisk og uegalitær negativ vri: "the employment of socialist practice with the aim of furthering Jewish colonialism!" ${ }^{48}$ Dette kommer ikke frem i informasjonen om kibbutzopphold fra Svekiv, Dankiv, MIFF eller israelske myndigheter. Man kan lure på om unge skandinaver ville dratt for å jobbe frivillig på kibbutz i den etnokratiske staten Israel, hadde de vært klar over den kontinuerlige kolonialisering og diskriminering de dermed støtter.

$$
\cdot f \cdot
$$

I Sitater fra Arbeiderbladet i Hilde Henriksen Waage, «Norge - Israels beste venn, Norsk Midøsten-politikk 1949-1956», S. 22, 1996.
2 Arthur Hertzberg, «The Zionist Idea», Harper and Row New York, s. 222, I959.

3 Waage, 1996, s.37

4 Waage, I996, s. 42-43.

5 Sitert i Waage, I996, s.22.

6 Tall på utvandringen av Palestinas arabiske befolkning varierer fra kilde til kilde. Jeg bruker her tall fra Benny Morris, «The Birth of the Palestinian Refugee Problem, I947-I949", Cambridge University Press, I987.

7 Se Nur Masalha, «Expulsion of the Palestinians: the Concept of "Transfer" i Zionist Political Thought, I882-I948», I992, Washington, D.C.: Institute for Palestine Studies, og Benny Morris, «Israel's Border Wars, 1949-1956: Arab Infiltration, Israeli Retaliation, and the Countdown to the Suez War», Oxford, Clarendon Press, I993.

8 Sitert i Waage, I996, s.22.

9 Se hjemmesiden: http://www.svekiv.se/. Det var tidligere en norsk versjon kalt Norkiv, men jeg har ikke klart å spore opp denne.

Io Naqab er det arabiske navnet, Negev det hebraiske/ israelske.

II For detaljer om beduinene i Naqab se Adalah hjemmeside, for eksempel http://www.adalah.org/eng/pressre leases/pr.php?file=2003_I2_07_AD_uncognised.

I2 Som beskrevet av henholdvis Waage (I996) og Øystein Jackwitz Rovde, "I solidaritetens navn, LOs forhold til Midtøstenkonflikten I947-2002", hovedfagsoppgave i historie, Universitet i Oslo, 2004.

I3 "Former kibbutz volunteers remember the good old days", Haaretz, 07.06.2005.

I4 Ibid.

I5 Jan Sigve Særsten, Kibbutz, Med Israel for fred, http://www.miff.no/kibbutz/index.htm.

I6 Mange kibbutzer har de siste tiårene blitt mer og mer kapitalistiske og i flere kibbutzer foretrekker medlemmene lønn istedetfor mat i matsalen og felles vaskeri etc.

I7 Jan Sigve Særsten, Kibbutz, Med Israel for fred, http://www.miff.no/kibbutz/index.htm.

I8 Jon Fidler, "Kibbutz, What, Why, When, Where", http://www.mfa.gov.il/MFA/MFAArchive/2000_2009/ 2002/II/Focus\%200n\%2OIsrael-\%20Kibbutz

I9 http://www.svekiv.se/dk/

20 "Former kibbutz volunteers remember the good old days", Haaretz, 07.06.2005.

2I Ibid.

22 Ibid.

23 MIFF beskrives som en Israel-vennlig organisasjon på hjemmesidene: http://www.miff.no/omiff.htm. 
24 Jan Sigve Særsten, Kibbutz, Med Israel for fred, http://www.miff.no/kibbutz/index.htm.

25 http://www.mfa.gov.il/MFA/MFAArchive/2000_2009 /2002/II/Focus\%2oon\%2oIsrael-\%2oKibbutz:

26 Dr. Salman Abu-Sitta, The Great Israel Land Grab, http://www.plands.org/articles/7.htm.

27 Ibid.

28 For detaljer se ILAs hjemmesider: http://www.mmi.gov.il/ envelope/indexeng.asp.

29 For detaljer se Adalah hjemmesider: http://www.adalah. org/eng/intladvocacy/JNFUNCHR.pdf\#search=\%22habi tat $\% 22$

30 Se Yiftachel, Oren, “'Ethnocracy” and its Discontents: Minorities, Protest and the Israeli Polity", Critical Inquiry, 26:725-756 (summer), 2000.

3I Det militæret styret av arabiske palestinere fra I948-I966 forhindret disse å bevege seg fritt, i å uttale seg fritt og deres økonomiske muligheter, se Gershon Sharif og Yoav Peled, «Being Israeli, The Dynamics of Multiple Citizenship, Cambridge, s. II2, 2002.

32 For flere detaljer om denne saken se Adalah: http://www.adalah.org/newsletter/eng/augo4/4.php

33 http://www.theunrecognized.org/

34 For flere detaljer om beduinene og palestinske statsborgere i Israel, se the Arab Association for Human Rights: http://www.arabhra.org/factsheets/factsheet4.htm og Mossawa, The Advocacy Center for Arab Citizens in Israel: http://www.mossawacenter.org/en/about/ about.html

35 Gershon Sharif og Yoav Peled, 2002, s.80.

36 For detaljer se Shlomo Swirski, «Israel - The Oriental Majority, Zed Books Ltd, London, I989.

37 Delen om Regnbuebevegelsen er basert på forskning forbindelse med min doktorgrad med arbeidstittel "Mizrahiut and the Arab-Jewish Divide in Israel - Contemporary Challenges to Israel's Ethnic Boundaries" til levering ved IKOS, UiO. For detaljer se også Rengbue bevegelsen sine hjemmesider: http://www.ha-keshet.org.il/

38 Shiko Behar, "Stop the occupation or stop the kibbutzim?", News From Within, vol. XVI, no. 4, April, 2000.

39 Gershon Shafir, "Zionism and Colonialism: A Comparative Approach", i «The Israeli/Palestine Question», red. Ilan Pappe, Routlegde, London, s. 89, I999.

40 Gershon Sharif og Yoav Peled, 2002, s. 74.

4I Ibid, s.76.

42 Ibid.

43 Sitert i Øystein Jackwitz Rovde, 2004, s. 45

44 Reuven Abarjel and Smadar Lavie, "Another Act in the Mizrahi-Palestinian Tragedy", The Electronic Intifada, 24 July, 2006.
45 Jan Sigve Særsten, Kibbutz, Med Israel for fred, http://www.miff.no/kibbutz/index.htm

46 Kibbutzim, Midtøsten i fokus, 26. januar 200I, http://www.miff.no/moif/index.htm

47 Sitert i Waage, I996, s.23.

48 Shafir, I999, s. 89. 